\section{Regional Modeling for Estimation of Runoff from Ungauged Catchments: Case Study of the Saptakoshi Basin, Nepal}

\author{
Jayandra Prasad Shrestha, Knut Alfredsen and \\ Netra Timalsina
}
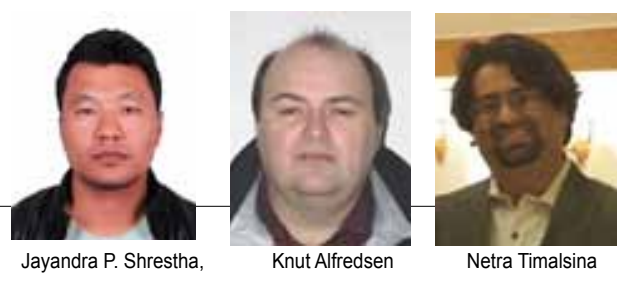

Abstract: In a mountainous country like Nepal, most of the gauge stations are located at low altitudes, and getting reliable hydrological data at intake sites, most of which are located at high mountains, is difficult. The main objective of the study is to apply the ENKI model system in a regional calibration of the Saptakoshi Basin and to test the reliability of the model in this area and extract the runoff at ungauged sites. ENKI is a modular framework to implement hydrological models, which operates on distributed data within a spatial region. Models can be created by a set of user-defined subroutines to custom design the functionality, and the model can be calibrated in a region making it suitable for prediction in ungauged catchments. Climatic data from 1999 to 2008 are used for the model calibration in the Saptakoshi Basin. While processing data, some errors and inconsistencies in the flow data were found, and this reduced the potential calibration sites in the catchment. The results showed that the modeled discharge of independent and upstream catchments were well in agreement with observed data, while less agreement was found with downstream basins where observed data were inconsistent. Good quality observation data and the availability of enough data govern the quality of the simulation with the model, so the importance of data quality cannot be disregarded. Finally, the obtained regional parameters were applied to extract the runoff data at the intake site of the Tamor hydropower plant. Further improvement of simulation results can be achieved with good quality of data and thus uncertainties in the parameters can be reduced. Even though there are some uncertainties in the results of model, the conclusion of this study is that the regional model, ENKI, could be a very helpful tool to predict the hydrological variables at the ungauged basins in a mountainous country like Nepal.

Key words: Regional modeling, ENKI, ungauged catchments, Saptakoshi Basin, Nepal

\section{Introduction}

$\mathbf{R}_{\text {unoff of rivers and the available head are the main }}$ from nature. The available head can be simply derived from a topographic map, and runoff can be found from various sources with varying degree of accuracy and costs, such as runoff maps, hydrological databases, runoff measurements, scaling or correlation with neighbor gauge stations. In the case of Nepal, specific runoff maps are not available yet, and most of the gauge stations are at low elevation. So, there is a great challenge in getting reliable hydrological data at the intake sites, most of which are at the high mountains, which are far from the existing gauges and also at higher elevations. The main purpose of this study is to estimate runoff in ungauged streams by using a regional rainfall runoff model as a potential method for future estimations.

A regional hydrological model allows the prediction of the dynamics of hydrology and the statistics of hydrological variables at the ungauged basins. Regional hydrological modeling implies a repeated use of a model at every sub-catchment within a region using a global set of parameters (K. Engeland, 2006). Observations for calibration and validation of the model are only available at a subset of sites where the model is applied. So, the regional model finds the best fit single parameter set for the entire region, which makes it possible to simulate ungauged catchments.

In our case the ENKI model system, developed by SINTEF Energy (http://www.opensource-enki.org/,
2013), is applied to the Saptakoshi Basin (Nepal) to test the reliability of the model in this area. The model is set up and calibrated to obtain a regional parameter set in order to get a good fit between the observed and simulated variables for all target catchments. From this regional parameter set, the runoff at ungauged sites can be simulated to estimate hydropower generation capacity and other purposes like irrigation and flood forecasting.

\section{Materials and Methods Saptakoshi River Basin}

The Koshi River, also called the Saptakoshi, is the largest river basin of Nepal, and has seven Himalayan tributaries: the Tamor River, Arun River, Dudhkoshi River, Likhu River, Tamakoshi (Bhotekoshi) River, Sunkoshi River and Indrawati River. Some of the rivers of the Koshi system, such as the Arun, Sunkoshi and Tamakoshi originate in Tibet. The location of the confluence of the three major tributaries, namely, Arun, Tamor and Sun Koshi rivers is at $26^{\circ} 54^{\prime} 47^{\prime \prime} \mathrm{N}$ and $87^{\circ} 09^{\prime} 25^{\prime \prime} \mathrm{E}$, at Tribeni, Nepal. According to the Department of Hydrology and Meteorology (DHM) Nepal, the Koshi River comprises an area of about 54,100 $\mathrm{Km}^{2}$ at the Chatara-Kothu gauge station and drains the eastern part of the country. Out of the total catchment area, $29,400 \mathrm{Km}^{2}$ of the Koshi catchment area lies in China (Tibet) and the remaining in Nepal. The highest elevation in this basin is 8848 amsl (Mt. Everest) to the lowest elevation to 140 masl. 


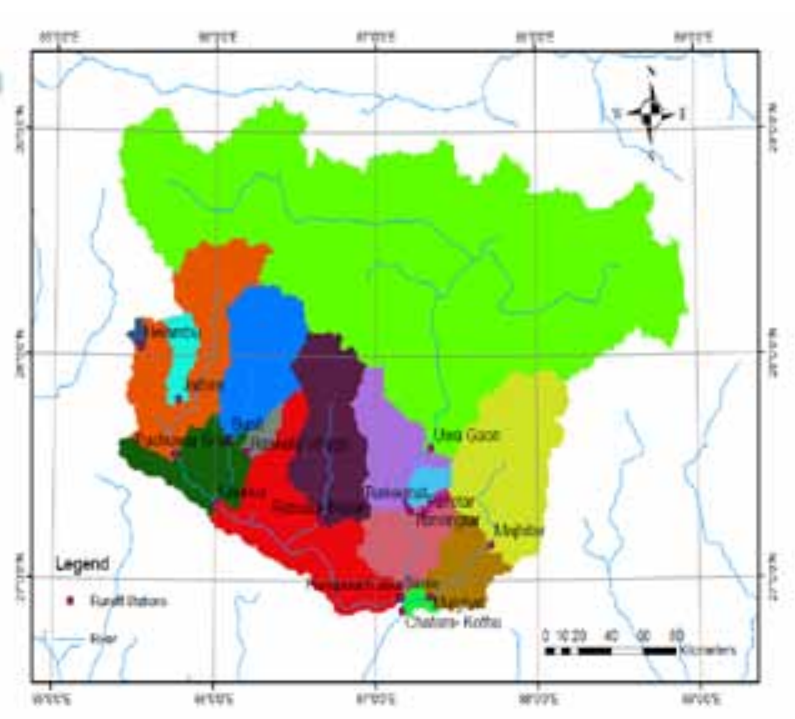

Figure 1. Gauge stations at Saptakoshi basin

The sub-catchments of the Saptakoshi and their areas at the gauge stations are shown Table 1 and Figure 1.

\section{Data collection and processing}

The 10 year hydro-meteorological data from 1999 to 2008 was obtained for the Saptakoshi Basin from the DHM, Nepal.

- Rainfall data for the Koshi Basin and around the basin were collected from the DHM, Nepal. There are altogether 67 precipitation stations. Almost half of the total catchment area lies in Tibet (China) and information from those parts are unavailable, which poses an element of uncertainty in this study.

- Air temperature data were also collected from the DHM, Nepal. The temperature data were in the form of daily mean values. Among these, 67 precipitation stations, air temperature data were available from only 18 respective stations. Temperature data from the remaining precipitation stations were interpolated.

- There are very few evaporation stations in Nepal. Three evaporation stations were found in the Saptakoshi Basin, and 10 year data were collected from these stations for model simulation.

- Daily discharge of 16 gauge stations from 1999 to 2003 were used for model calibration, and the remaining 5 year data were used for model validation. The other input files for ENKI were digital maps of point networks (precipitation, temperature, evaporation and runoff), catchment areas, a Digital Elevation Model (DEM) of the basin and a land use of the study area.

The summary of hydro-meteorological data is exhibited in Table 2 below:

\begin{tabular}{|l|c|c|c|c|}
\hline \multirow{2}{*}{ Daily data } & \multicolumn{3}{|c|}{ No. of stations } & \multirow{2}{*}{ Time series } \\
\cline { 2 - 4 } & Collected & $\begin{array}{c}\text { Inter } \\
\text { polated }\end{array}$ & $\begin{array}{l}\text { Total } \\
\text { stations }\end{array}$ & \\
\hline Precipitation & 67 & - & 67 & $1999-2008$ \\
\hline Temperature & 18 & 49 & 67 & $1999-2008$ \\
\hline Evaporation & 3 & - & 3 & $1999-2008$ \\
\hline Runoff & 16 & - & 16 & $1999-2008$ \\
\hline
\end{tabular}

Table 2. The summary of hydro-meteorological data

\section{Data Quality in Basin}

The most challenging task was to get good quality runoff data from the Saptakoshi Basin. The quality of runoff data was checked by calculating runoff from local catchments by subtracting the upstream gauged flow from the downstream gauged flow. The runoff of the local catchment should show a positive value unless there are some errors in the data or diversion works at the upstream of gauge station.

\begin{tabular}{|c|c|c|c|c|c|c|c|c|c|c|}
\hline \multirow{2}{*}{$\begin{array}{l}\text { S. } \\
\text { No }\end{array}$} & \multirow{2}{*}{$\begin{array}{l}\text { Staion } \\
\text { Index }\end{array}$} & \multirow{2}{*}{ Name of River } & \multirow{2}{*}{ Location } & \multirow{2}{*}{ Latitude(N) } & \multirow{2}{*}{$\begin{array}{c}\text { Longitude } \\
\text { (E) }\end{array}$} & \multirow{2}{*}{$\begin{array}{c}\text { Elevation } \\
(\mathrm{m})\end{array}$} & \multicolumn{2}{|c|}{ Catchment Area (Sqkm) } & \multirow{2}{*}{ Discrepancy } & \multirow{2}{*}{$\begin{array}{l}\text { Local CA } \\
\text { (Sqkm) }\end{array}$} \\
\hline & & & & & & & From DHM & From GIS & & \\
\hline 1 & 600.1 & Arun & Uwa Gaon & 273521 & 872022 & 1294 & 26750 & 29616 & $11 \%$ & 29616 \\
\hline$\underline{2}$ & 647 & Tamakosi & Busti & 273805 & 860512 & 849 & 2753 & 2898 & $5 \%$ & 2898 \\
\hline 3 & 695 & Saptakosi & Chatara- Kothu & 265200 & 870930 & 140 & 54100 & 58053 & $7 \%$ & 200 \\
\hline 4 & 681 & Sunkosi & Hampuachuwar & 265515 & 870845 & 150 & 18700 & 17936 & $-4 \%$ & 4315 \\
\hline 5 & 627.5 & Melamchi & Helambu & 280221 & 853207 & 2134 & 84 & 117 & $39 \%$ & 117 \\
\hline 6 & 602.5 & Hinwakhola & Pipletar & 271745 & 871330 & 300 & 110 & 112 & $2 \%$ & 112 \\
\hline 7 & 620 & Balephi & Jalbire & 274820 & 854610 & 793 & 629 & 659 & $5 \%$ & 659 \\
\hline 8 & 652 & Sunkosi & Khurkot & 272011 & 860001 & 455 & 10000 & 10201 & $2 \%$ & 1974 \\
\hline 9 & 684 & Tamur & Majhitar & 270930 & 874245 & 533 & 4050 & 4530 & $12 \%$ & 4530 \\
\hline 10 & 690 & Tamur & Mulghat & 265550 & 871945 & 276 & 5640 & 6008 & $7 \%$ & 1477 \\
\hline 11 & 630 & Sunkosi & Pachuwar Ghat & 273330 & 854510 & 602 & 4920 & 5004 & $2 \%$ & 4227 \\
\hline 12 & 670 & Dudhakosi & Rabuwa Bazar & 271614 & 864002 & 460 & 4100 & 3419 & $-17 \%$ & 3419 \\
\hline 13 & 650 & Khimtikhola & Rasnalu Village & 273430 & 861150 & 1120 & 313 & 326 & $4 \%$ & 326 \\
\hline 14 & 602 & Sabayakhola & Tumlingtar & 271836 & 871245 & 305 & 375 & 406 & $8 \%$ & 406 \\
\hline 15 & 606 & Arun & Simle & 265542 & 870916 & 152 & 30380 & 33503 & $10 \%$ & 1721 \\
\hline 16 & 604.5 & Arun & Turkeghat & 272000 & 871130 & 414 & 28200 & 31670 & $12 \%$ & 2053 \\
\hline
\end{tabular}

Table 1. Description of the rivers and gauge stations in the Saptakoshi basin 
There are nine gauged sub-catchments in the Saptakoshi Basin: Majhitar, Uwa Gaon, Pipletar, Tumlingtar, Rabuwa Bazar, Rasnalu Village, Busti, Jalbire and Helambu. For these catchments, the above method was used to check the quality of the runoff data. The runoff from the local catchment at the stations Simle, Hampuachuwar and Chatara-Kothu were almost all negative during the monsoon (Figure 2). Hence these catchments were excluded from the model calibration, which is a problem in a system with already scarce data, providing further uncertainty for the regional calibration. The source of errors may be due to observations or instruments. Another issue is that almost half of the Koshi catchment lies in the Tibetan region and the precipitation and climatic pattern of Tibet is different than that of Nepal. Since the availability of climatic data from the Tibetan area is difficult, this is another source of uncertainty in the assessment.

\section{ENKI}

ENKI is a modular framework to implement lumped or distributed hydrological models. Within the ENKI framework, a model can be created by combining a set of existing userdefined subroutines or by developing new routines that are included in the framework. The model is interfaced with spatial data formatted using a Geographic Information System (GIS), parameters and time series of input data all controlled within the ENKI framework.

The ENKI project has been a part of a research and development agreement between SINTEF Energy and Statkraft, and work has gone on for five years (http://www.opensourceenki.org/, 2013). The ENKI modeling system is equipped with tools for regional model setup, calibration and uncertainty analysis. In a regional model, a common parameter set for an entire region is found, and through this inflow from ungauged sites within the region can be extracted with a measure of uncertainty derived from the calibration. The ENKI system is an open source software, freely available for download from the above site.

The calibration and evaluation functionality of ENKI makes it easy for model practitioners to build simple or more advanced model setups within a defined framework. ENKI is written in the $\mathrm{C}++$ language and uses a plug-in structure to invoke separately developed subroutines stored in dynamic-link libraries (DLLs). All subroutines are coded as sub-classes of a generic method class, which is controlled by the ENKI framework providing the modeler with control of timing and dataflow. The framework also contains the administrative and user interfaces. The number, types, and names of each subroutine's variables are recognized by this framework and exposed to the user at the time of model setup, ensuring that distributed map coincide spatially, time series exist for input variables, states are initialized, GIS data sets exist for static map data, manually set parameters or by auto calibration (Kolberg, S. and Bruland, O., 2012).

\section{The HBV model}

The HBV (Hydrologiske Byrån avdeling för Vatten balans) model is a conceptual precipitation-runoff model used to simulate runoff from a catchment based on precipitation, air temperature and potential evapo-transpiration. The HBV model was developed by Dr. Sten Bergström at the Swedish Meteorological and Hydrological Institute (SMHI) (Bergstrøm and Forsman, 1973). It is based on a conceptual representation of the main components of the land phase of the hydrological cycle as shown in Figure 3. Runoff from a catchment is computed from meteorological data like precipitation, air temperature, and potential evaporation.
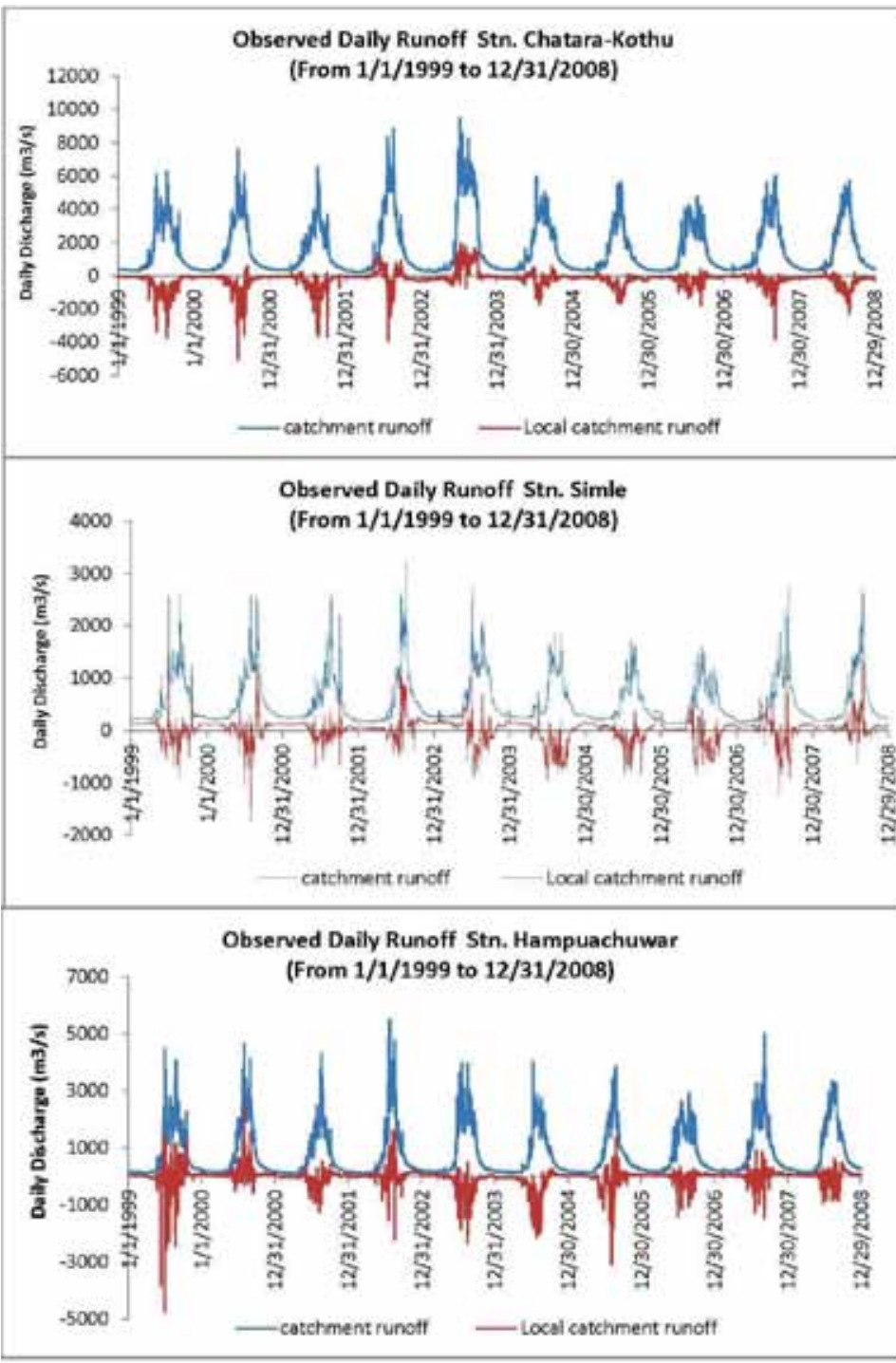

Figure 2. Comparisions of observed Catchment runoff and derived local catchment runoff from the observed data 


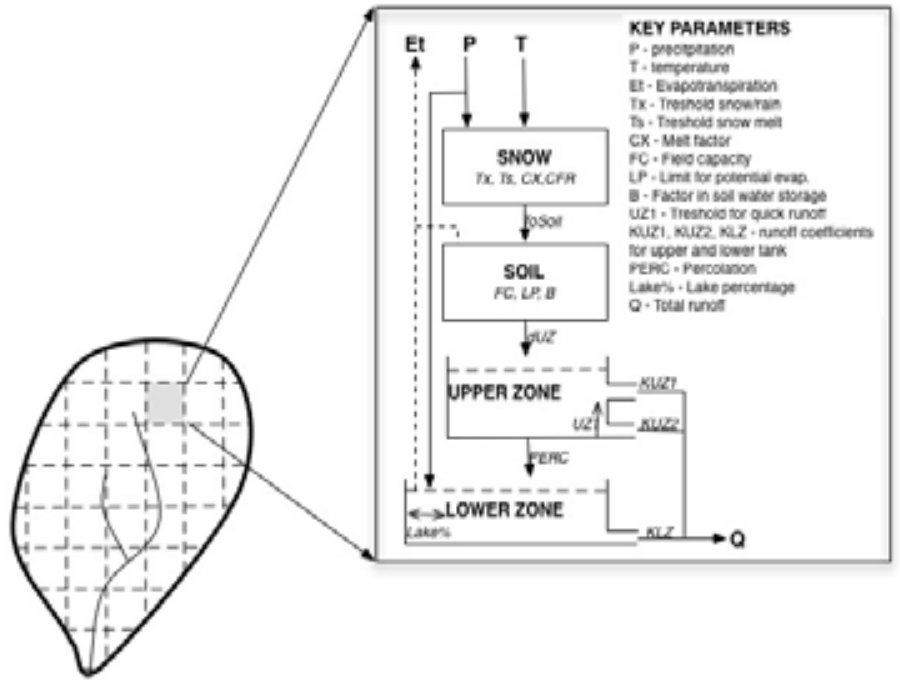

Figure 3. The principle of running the HBV model (model structure shown to the right) distributed in a gridded catchment. The model was built using the ENKI modular model setup, and ENKI controlled the grid structure and data flow

The standard version of the HBV model has four main components: Snow, Soil moisture, Upper zone and Lower zone. In the distributed setup used in this project, the HBV is used distributed so that a single HBV runs in each cell in the distributed catchment.

\section{Regional modeling with ENKI}

The pre-built subroutines of the HBV-model within the ENKI framework were configured for the regional model calibration in the Saptakoshi catchment i.e. the aggregated HBV-model output for a set of gauged subcatchments is calibrated at the same time and evaluated based on the average response. The best parameter sets of the region, obtained by the regional model calibration, were fit for all the sub-catchments of the region enabling an estimation of the uncertainty also for ungauged catchments. This, in contrast to the traditional onecatchment approach, where the calibrated parameters could be used only for the basin they were derived for. The regional hydrological modeling implies the repeated use of a model everywhere within a region using a regional set of parameters as shown in Figure 4. The regional model allows for various responses from various parts of the catchments, and emphasizes interpolation and downscaling of input data.

\section{Calibration}

The calibration of the model can be carried out in two ways in the ENKI system. One option is manual calibration were the user changes parameters manually, and another option is automatic calibration were a search algorithm finds the best parameters set from repeated model runs. There are currently five different automatic methods implemented, and among these, are the SCE-UA (Shuffled Complex Evolution Method developed at The University of Arizona) method is used in this study (Q. Duan, 1992). This is a global optimization method that is considered as an efficient optimization technique for calibrating watershed models. The Nash-Sutcliffe efficiency index $\left(\mathrm{R}^{2}\right)$ is used to assess the performance of a hydrologic model.

$R^{2}=1-\frac{\sum\left(Q_{s}-Q_{0}\right)^{2}}{\sum\left(Q_{0}-Q a v e_{0}\right)^{2}}$

Where,

$\mathrm{R}^{2}=$ Nash-Sutcliffe efficiency index,

$Q_{n}=$ Observed discharge in $\mathrm{m}^{3} / \mathrm{s}$,

$Q_{s}=$ Simulated discharge in $\mathrm{m}^{3} / \mathrm{s}$,

Q ave $_{0}=$ Observed mean discharge in $\mathrm{m}^{3} / \mathrm{s}$,

$\mathrm{R}^{2}$ can vary from negative infinity to 1 , where ${ }^{1}$ is a perfect fit. In addition to the $\mathrm{R}^{2}$ criterion, the cumulative difference $\sum\left(Q_{s}-Q_{0}\right)$ is also used to determine the goodness of fit.

\section{Results}

The model was calibrated for 8 sub-catchments of the Saptakoshi Basin for the 5 year period from 1999 to 2003 as shown in Figure 5. As already mentioned above, the climatic data within the Tibetan region were not available, and erroneous runoff data at some gauge stations were found during data quality control, and this limited the available catchments. The one benefit of simulating only these catchments is that it reduced the accumulation of errors where flow measurements were inconsistent.
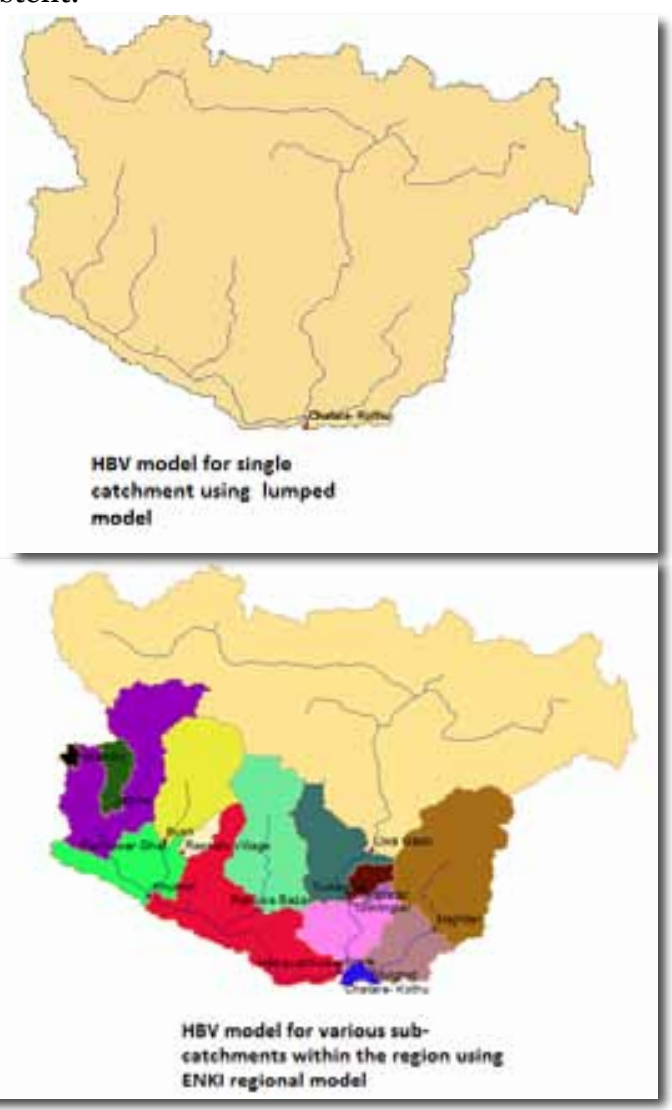

Figure 4. Application of HBV-model in a single catchment and for several catchments within a region using ENKI 


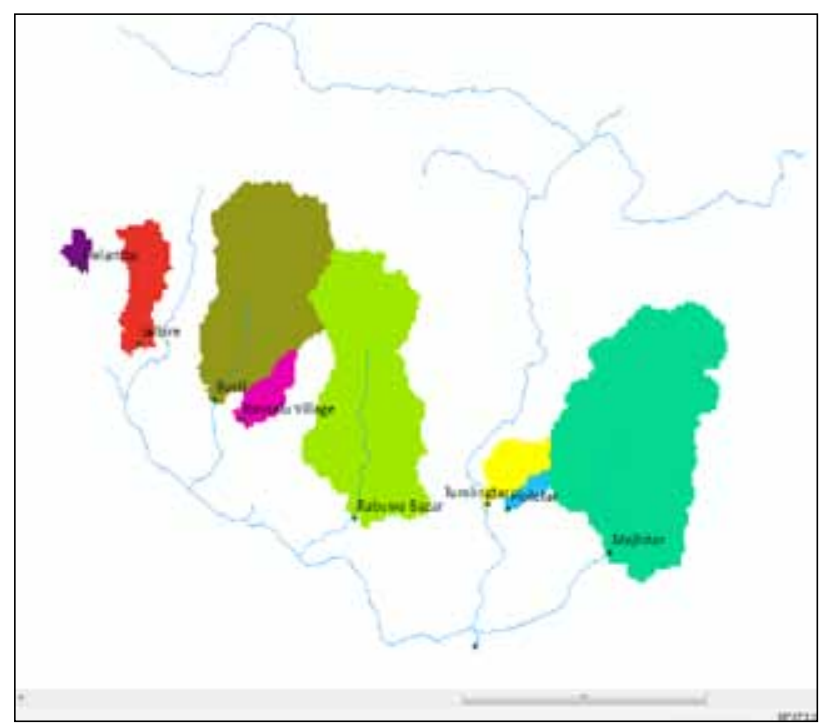

Figure 5. Sub-catchments of the Saptakoshi basin for calibration

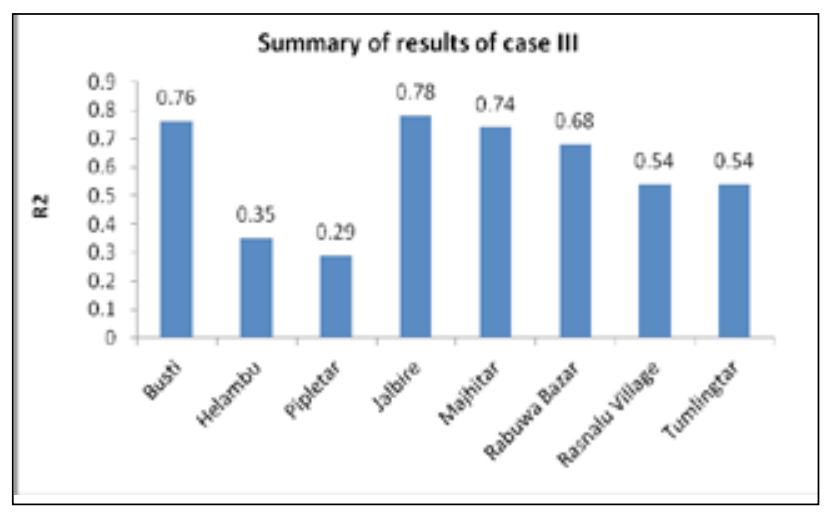

Figure 6 shows the $\mathrm{R}^{2}$ for the individual catchments, and Figure 7 the associated hydrographs for each Figure 6. Calibration results from 8 sub catchments in the Saptakoshi basin.

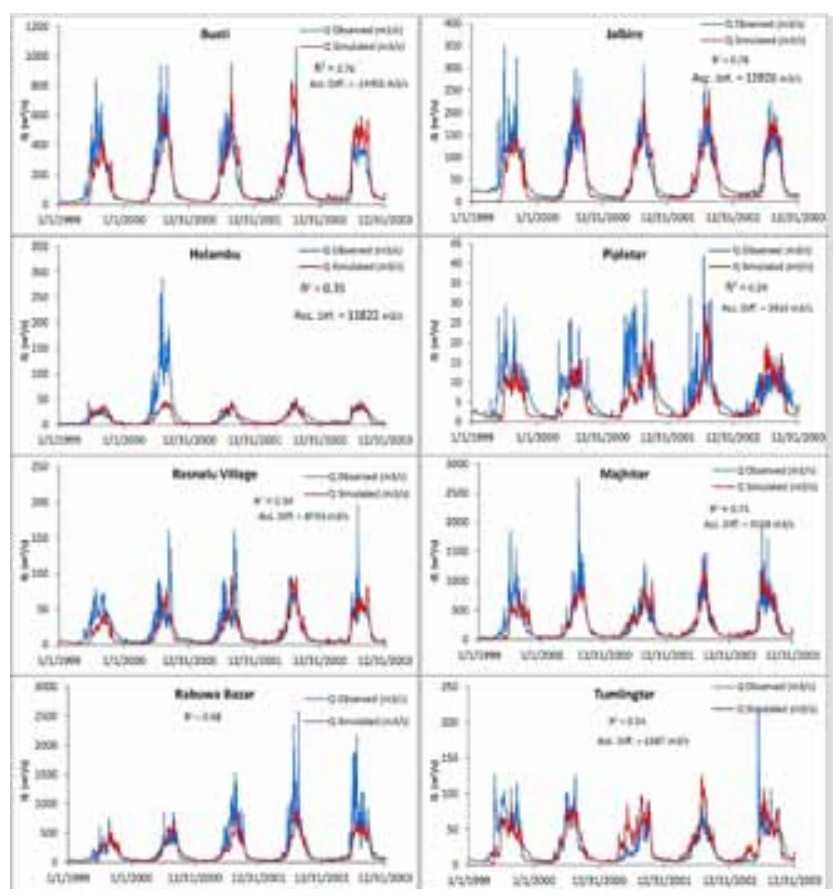

Figure 7.The observed and simulated daily discharges in $\mathrm{m} 3 / \mathrm{s}$

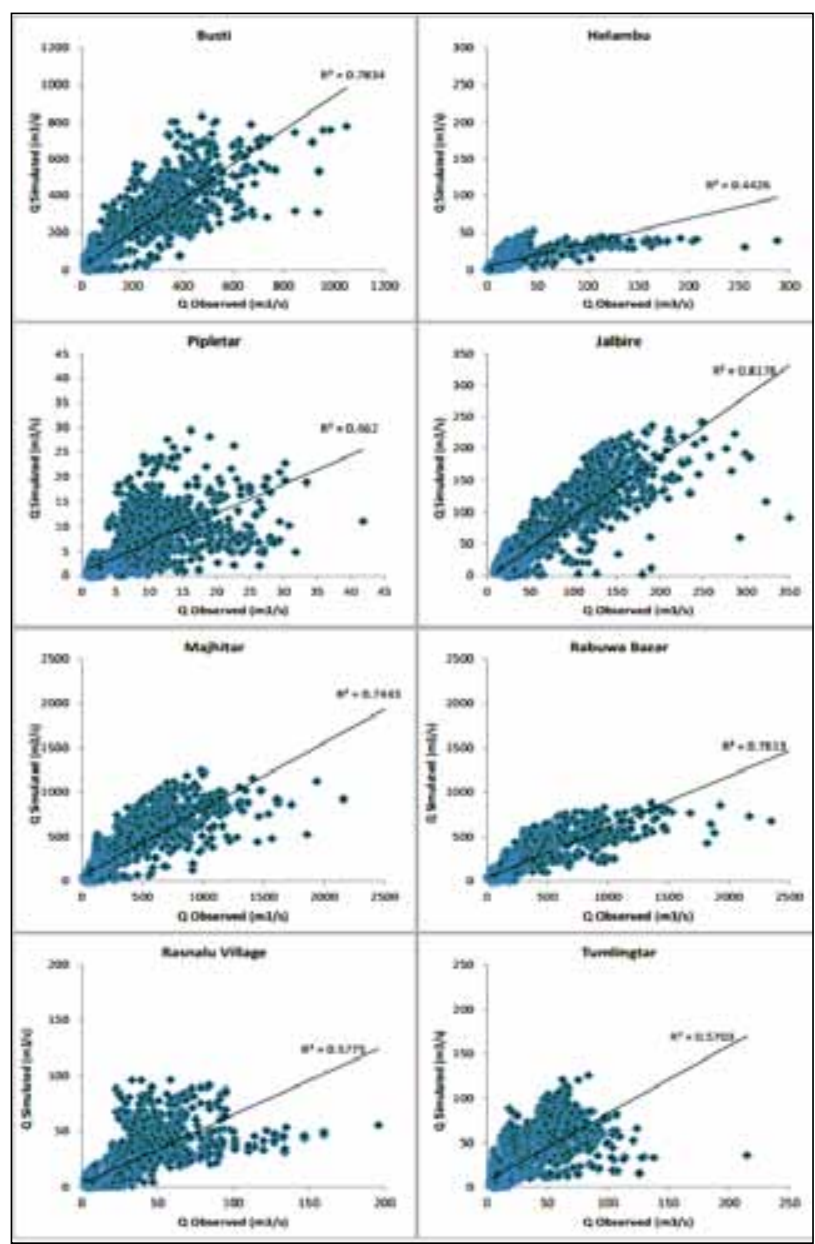

Figure 8. Scattered plots of the observed and simulated daily discharges in $\mathrm{m} 3 / \mathrm{s}$

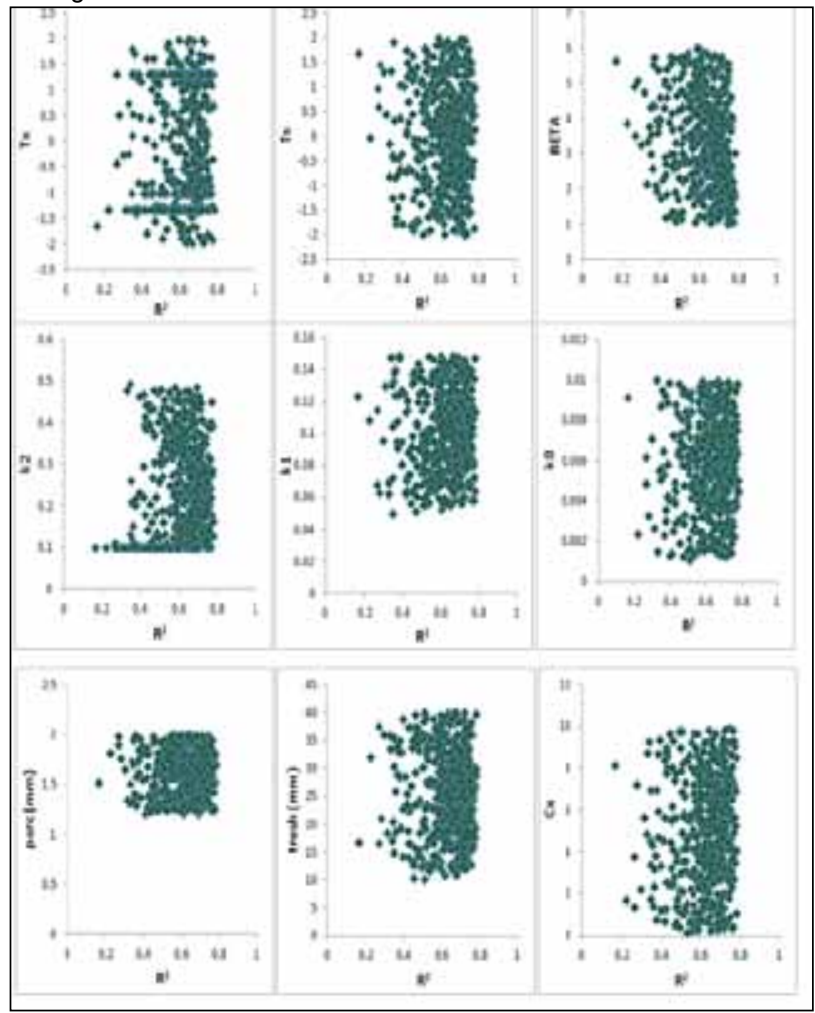

Figure 9. Scatter plots of R2 for calibration parameters for the Majhitar catchment. The plot indicates the range of good fit for each parameter and thereby the uncertainty of using a single parameter set. 
catchment. From these, it can be seen that the model fit is reasonably good for several of the catchments. It can also be seen that the model works better for larger catchments than for small, and particularly for Pipletar and Helambu, the $\mathrm{R}^{2}$ values are comparatively low. This might be due to flashy variations in the observed runoff, and for Helambu the inability of the model to simulate year 2000. This year is suspect since the flow value is much higher than any other year, and it cannot be seen that similar flooding might have occurred in any of the neighbouring catchments. Similarly, Figure 8 is a presentation of the same results in the form of scatter plots of the calibrated and observed discharges. In these scatter plots; the $\mathrm{R}^{2}$ values are little bit higher than in the above hydrographs.

The scatter plots of different parameters with respect to $\mathrm{R}^{2}$ are presented in Figure 9 for the Majhitar catchment. It can be seen from these figures how variations of the parameter values impact the $\mathrm{R}^{2}$. When these scatter plots are scrutinized, it can be noticed that the $\mathrm{R}^{2}$ values varied from 0.2 to 0.8 for the given ranges of parameter values. For example, a percolation (perc) parameter ranges from 1.5 to 2.0 gave the higher $\mathrm{R}^{2}$ values. So with the help of these plots, we can know the ranges of parameter values which give the higher goodness of fit $\mathrm{R}^{2}$ and, hence can achiev a good quality of calibration results. Among the parameters used in the model simulation, some were less sensitive to the output results such as maximum distance between stations and numbers of stations; which, therefore, were kept constant.

From the above plots, it can also be seen how the variations of the different parameters influence the performance of the model. It is also seen that there might be many combinations of parameter values that will provide almost equally good fits to the observed data (Duan et al. 1992; Beven 1993). There is not only one parameter set that can be selected as the best in simulating the system of interest; there is, consequently, a degree of model equifinality in reproducing the observations with model predictions. Thus, the uncertainty arising from parameter equifinality could further be analyzed and the presented hydrograph could be expanded with a confidence interval in addition to the most likely value presented here. This could then further be used to assess the potential uncertainty in the predicted inflow.

\section{Extraction of Runoff from Intake site: Tamor}

The main application of regional modeling in our case was to extract runoff data from ungauged sites within the modeled region. The intake sites situated at high altitudes have no measured data for long periods. The data can be extracted for these ungauged intake sites by using the regional parameter set of that region to simulate specific ungauged catchments. The calibrated parameters were used to extract the runoff data from the intake site of the Tamor hydropower project. The intake of the Tamor hydropower project is located at $27^{\circ} 29^{\prime} 40^{\prime \prime} \mathrm{N}$ and $87^{\circ} 46^{\prime} 59^{\prime \prime} \mathrm{E}$ and altitude of $1348.5 \mathrm{~m}$ (B. R. Paudel, 2010).

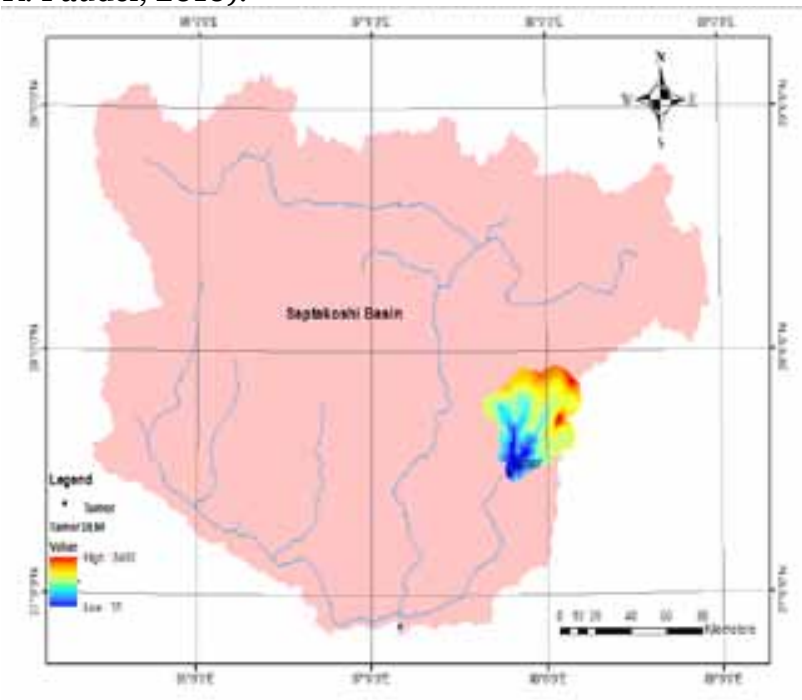

Figure 10. Location map and DEM of Tamor catchment

The actual measured runoff data at the intake site of the project were unavailable. The inflow at the intake site was interpolated by using the areal scaling factor of 0.42 (i.e. catchment correlation method) from Majhitar gauge station. In our case, the simulated runoff data from ENKI model using above parameters were compared to the scaled runoff data at Majhitar gauge station. The hydrographs are shown in Figure 11.

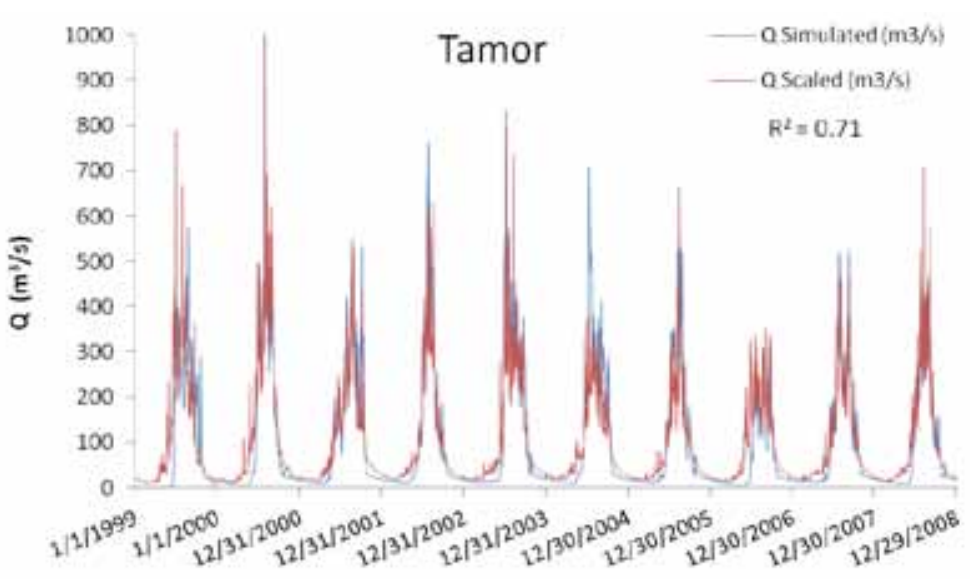

Figure 11. Hydrographs of simulated (from the regional model) and scaled runoff (from observed runoff) for Tamor Intake Site

The simulated and scaled runoff data were similar in pattern. The model was able to predict the average flows, but in case of instantaneous high floods, the model shows comparatively lower ability to meet the highest peaks. In the above flow duration curves, the simulated curve value at $40 \%$ of exceedance was less than the scaled curve. In Nepal, most of the hydropower plants are designed for flow at $40 \%$ of exceedance. An overestimation of the flow for a particular project might cause it to be uneconomic 


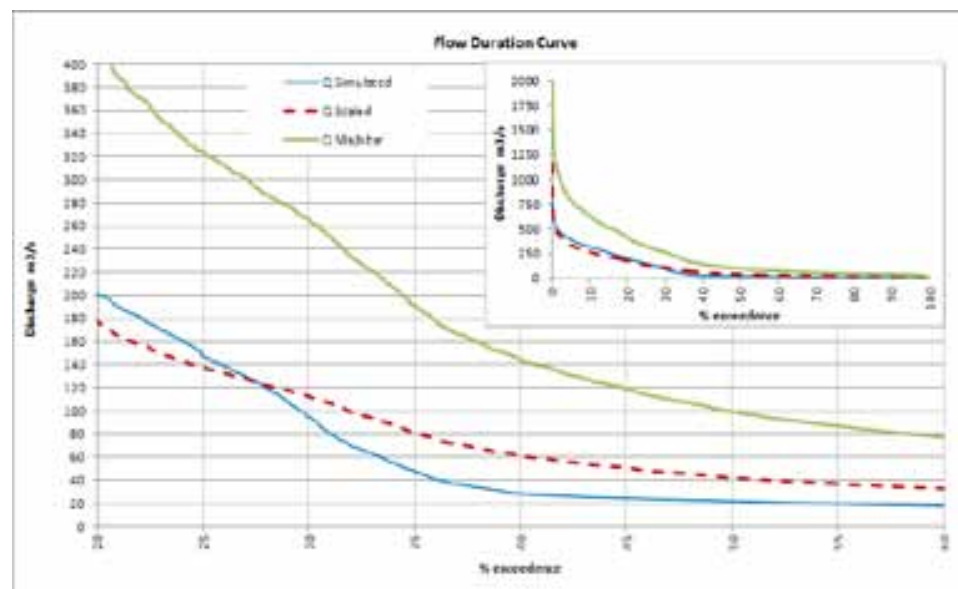

Figure 12. Comparison of Flow duration curves

and unreliable. The goodness of fit $\mathrm{R}^{2}$ between these two hydrographs is 0.71 and the accumulated difference between scaled and extracted stream flow for 10 years is $7352 \mathrm{~m} 3 / \mathrm{s}$. There are uncertainties in comparing these results because the actual intake site data were not available. However, this catchment is the upper part of the Majhitar catchment, and the simulation results of Majhitar were better than other catchments. Hence the extracted runoff should also be a good fit with the actual runoff at the intake site.

\section{Conclusion}

The ENKI modeling system with regional calibration was applied to the Saptakoshi Basin in Nepal for the first time. The calibrated regional parameter sets of the Saptakoshi Basin can be applied with a certain degree of confidence to ungauged catchments. Even though the quality of the observed runoff data reduced the number of catchments that could be included in the region, the simulation result of the model seems reasonable particularly for the largest catchments.

In case of the Nepalese landscape, one of the unique climatic patterns is flashy rivers and heavy rainfallrunoff. And the other main challenge for applying the model in Nepal is the lack of knowledge of the high altitude hydrology. There are other uncertainties such as the quality and, in some cases, lack of data to provide a representative view of, particularly, the high altitude areas.

It can be concluded that if the quality of the observed data is reliable, then the uncertainty of simulation results can be reduced. Even though there are uncertainties in the results of model, the conclusion of this study is that regional modeling, like the example presented in this paper, could be a very helpful tool to predict the hydrological variables at the ungauged basins in Nepal.

Jayandra Prasad Shrestha M. Sc., Hydropower Development, is a graduate in Civil Engineering at Tribhuvan University and has obtained Master's Degree at Norwegian University of Science and Technology
(NTNU). He has worked in design, construction and planning of hydropower projects in Nepal and Norway. He is currently working in ERMC P. Ltd., Kathmandu involving in feasibility study of different projects.

Corresponding address: shresthajayandra@ gmail.com

Knut Alfredsen $a \quad P h D \quad$ (in Hydraulic Engineering from NTNU) is a Professor at the Department of Hydraulic and Environmental Engineering, NTNU. He has been working at the department since 2002. His areas of research are hydrological modelling, cold climate hydrology and environmental impacts of hydropower. He has published 30 papers in international peerreviewed journals.

Corresponding address: knut.alfredsen@ntnu.no

Netra Timalsina holds Master's degree in Hydropower Development from the NTNU, currently a PhD student in the same university and working on Modeling of river ice in a complex hydropower setting. He has nearly 11 years of experience on hydropower planning, design and construction. His main field of interest is hydropower operation constraints and implication in cold climate, hydrological and hydraulic modeling, programming, instrumentation and primary field data collection.

Corresponding address: netra.timalsina@ntnu.no

\section{References}

A. Hreiche, D. Mezher, C. Bocquillon, A. Dezetter, E. Servat and W. Najem, "Parallel Processing for a Better Understanding of Equifinality in Hydrological Models", International Environmental Modelling and Software Society VOL 1, 2002.

A. Dixit, M. Upadhya, K. Dixit, A. Pokhrel, and D. R. Rai, "Living with Water Stress in the Hills of the Koshi Basin, Nepal," Institute for Social and Environmental TransitionNepal (ISET-N), ICIMOD, 2009. Available: http://www. opensource-enki.org/, 2013.

A. Killingtveit and N. R. Sælthun, Hydrology:Hydropower Development, v.7, Trondheim, Norway: Norwegian Institute of Technology, Division of Hydraulic Engineering, 1995.

Bergström S. and Forsman A., Development of a conceptual deterministic rainfall-runoff model. Nordic Hydrology, 4(3), 147-170, 1973.

B. R. Paudel, "Hydrological modelling of the Tamor hydropower Project," M.Sc. Thesis, Norwegian University of Science and Technology (NTNU), Trondheim, Norway, 2010. "DEMLab - a platform for the implementation and evaluation of distributed hydrological models," SINTEF Energy Research, 2008. Department of Hydrology and Meteorolgy (DHM), Nepal, 2011. Available: www.dhm.org.np

H. Madsen, "Parameter estimation in distributed hydrological catchment modelling using automatic calibration with multiple objectives," Advances in Water Resources, vol. 26, 
pp. 205-216, 2003.

J. Kadel, "Statistical Prediction of Seasonal Rainfall in Nepal," APEC Climate Center, Kathmandu, Nepal, 2012.

K. Engeland, I. Braud, L. Gottschalk, and E. Leblois, "Multiobjective regional modelling," Journal of Hydrology, vol. 327, pp. 339-351, 2006.

K. Engeland, L. Gottschalk, and L. Tallaksen, "Estimation of Regional Parameters in a Macro Scale Hydrological Model, 2001."

K. J. Beven, "Equifinality and Uncertainty in Geomor phological Modelling", In: Rhoads, B.L. and Thorn, C.E. (eds) The Scientific Nature of Geomorphology: Proceedings of the 27th Binghamton Symposium in Geomorphology. John Wiley and Sons: Chichester, U.K., 289-314. Available on the web: http:// geoinfo.amu.edu.pl/wpk/natgeo/contents.html, 1996.

K. J. Beven, Rainfall-Runoff modelling, The Primer, 2000.

K. J. Beven, Rainfall-Runoff Modelling: The Primer: John Wiley \& Sons, 2012.

K. P. Sharma, "Role of Meltwater in Major River Systems of Nepal," International Association of Hydrological Sciences, Snow and Glacier Hydrology,Department of Hydrology and Meteorlogy, Nepal, 1993.

Subramanya, Engineering Hydrology, 2nd ed., 1994.

N. P. Timalsina, "Hydrological Modelling of the Upper Trishuli 3A Catchment in Nepal. Comparison of Lumped and Distributed
Models," M.Sc. Thesis, Norwegian University of Science and Technology (NTNU), Trondheim, Norway, 2008.

P. H. M. Janssen and P. S. C. Heuberger, "Calibration of processoriented models," Ecological Modelling, vol. 83, pp. 55-66, 1995.

Q. Duan, S. Sorooshian, and V. Gupta, "Effective and efficient global optimization for conceptual rainfall-runoff models," Water Resour. Res., vol. 28, pp. 1015-1031, 1992.

Q. Duan, S. Sorooshian, and V. K. Gupta, "Optimal use of the SCEUA global optimization method for calibrating watershed models," Journal of Hydrology, vol. 158, pp. 265-284, 1994.

S. K. Jain and K. P. Sudheer, "Fitting of Hydrologic Models: A Close Look at the Nash--Sutcliffe Index," Journal of Hydrologic Engineering, vol. 13, pp. 981-986, 2008.

S. Kolberg and O. Bruland, "ENKI - An Open Source environment modelling platform”, 2012.

S. Shrestha and K. Alfredsen, "Application of HBV Model in Hydrological Studies of Nepali River Basins: A Case Study", Hydro Nepal: Journal of Water, Energy and Environment, Issue No.8, January 2011.

V. T. Chow, Maidment, D.R. \& Mays, L.W, Applied Hydrology, 1989.

Z. Yu, "HYDROLOGY | Modeling and Prediction," in Encyclopedia of Atmospheric Sciences, R. H. Editor-in-Chief: James, Ed., ed Oxford: Academic Press, 2003, pp. 980-987.

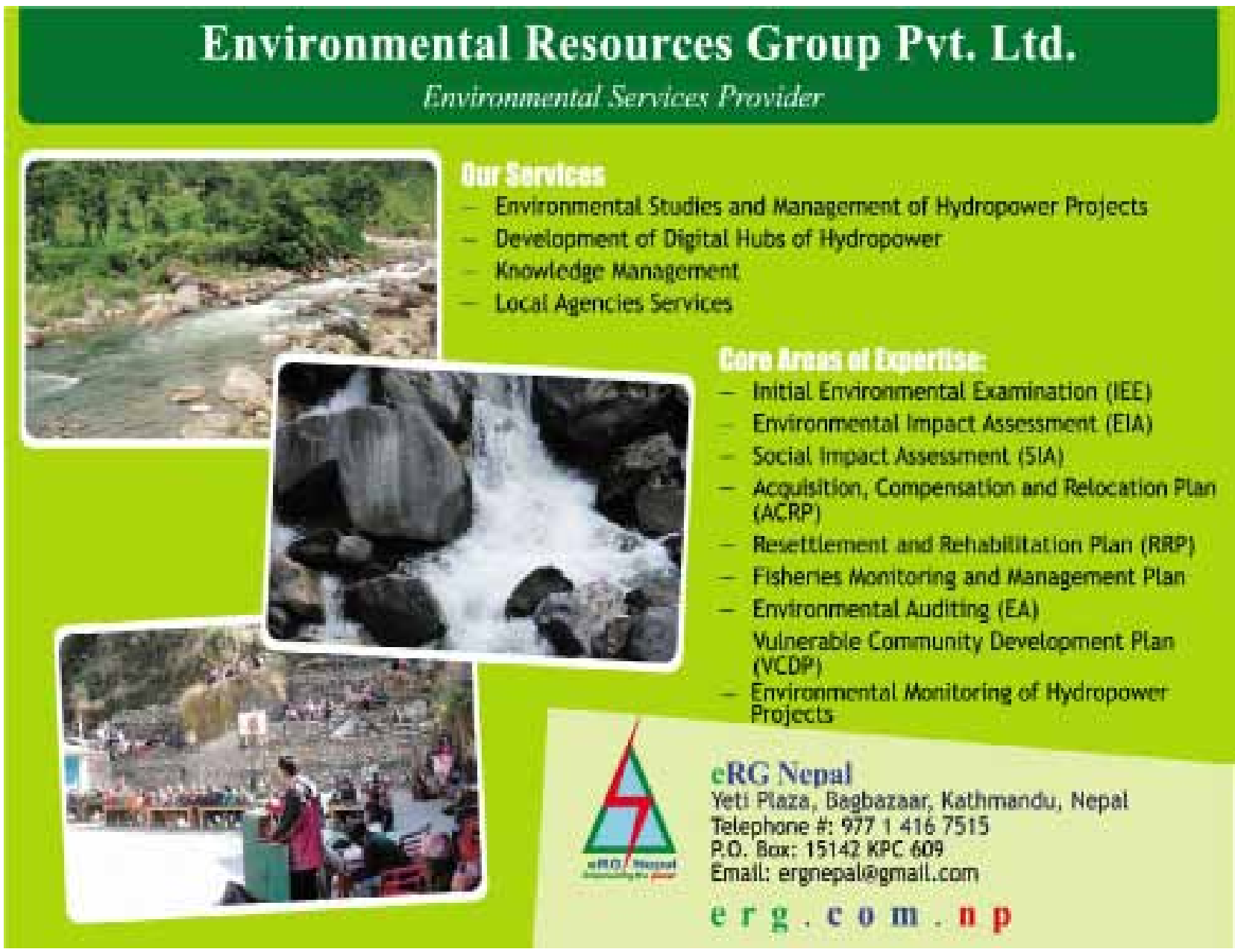

